\section{Memorias, performatividad y catástrofes: \\ Ciudad interrumpida}

\author{
Rossana Reguillo
}

Edmundo Dantés no ha perdonado. Es un obseso del pasado. Y esta es su segunda desgracia: en busca de la memoria solo encuentra el olvido.

MarC Augé (LAS FORMAS DEL OLVIDO)

a víctima se ha instalado en el paisaje contemporáneo como un "lugar" densamente cargado de significado y visibilidad. Es la víctima la que narra para "el nuevo periodismo", obsesionado por conquistar el lugar sin mediaciones, la nota cruda, la voz que proviene de la auténtica experiencia límite y que, por tanto, no admite refutación, es la víctima la que llena los prime time, la que garantiza un zapping favorecedor; y, sobre todo, es la víctima la encarnación del último reducto de la lucha o el caso testigo del colapso final. Para los que comparten una catástrofe hay pocas opciones, en lo fáctico, están condenados a perderse en el anonimato de la desesperación y la constatación del fin; pero en lo mediático, pueden acceder a un mínimo espacio de voz en primera persona y a un protagonismo efímero que arranca emociones entre los espectadores, lo que a su vez deviene en una pequeña posibilidad de abandonar su condición de víctima.

La víctima configura un pequeño espacio de conciencia, su tarea es devenir señal postsintomática a través de la cual es posible captar los indicios de un orden fallido en el que "algo" se 
rompe, se descompone y, en tal sentido, la víctima proyecta un recuerdo anticipado de una ausencia de orden, de sentido, de legibilidad, ella opera una solución de continuidad entre el pasado y el futuro, instalándose en un presente permanente en el que queda fijada la tragedia, la catástrofe. Su condición la habilita para inaugurar un espacio, un territorio en el que se condensan las señales, los símbolos, las metáforas: las plazas, un recinto, una calle, cuyas historias quedan atadas al acontecimiento que trastoca para siempre su sentido de ser y de existir.

Por ello, pese a su secuestro mediático y a su banalización contemporánea, la víctima, el actor, el protagonista de la catástrofe, de la violencia sistémica constituye un espacio privilegiado para pensar la dimensión sociopolítica y cultural de las políticas del recuerdo, porque me parece que ella actúa como epicentro de dimensiones claves para situar y restituir complejidad política a los dispositivos de la memoria: acontecimiento, lugar y dramatización (o performatividad).

Quiero, entonces, partir de una perspectiva antropológica para acercarme a las relaciones multidimensionales entre catástrofe, performatividad y memoria, utilizando dos casos testigo, dos arraigos empíricos que operan tanto como anclajes específicos de mi reflexión como dispositivos para un análisis de segundo orden, es decir, teórico. Se trata de las explosiones por gasolina ocurridas en la ciudad de Guadalajara en abril de 1992, que ocasionaron más de doscientos muertos e innumerables tragedias, y del incendio ocurrido en una discoteca en Buenos Aires, Cromañón, ocurrido la madrugada del 30 de diciembre del 2004, que le costó la vida a 197 jóvenes y levantó una ola de protesta social.

Ambos acontecimientos comparten tres características fundamentales para este análisis: se inscriben en lo que la literatura especializada sobre desastres denomina "desastres antropogénicos", es decir causados por agentes humanos; movilizaron fuertes procesos de reflexividad "urbana" y estrategias de acción dramatúrgica -performatividadmuy vinculados a los dispositivos de la creencia religiosa.

En una interesante y nada transparente amalgama, la religiosidad popular operó en ambos casos como un lenguaje político que articuló la protesta e inauguró santuarios -profanospara la memoria o, visto desde otra perspectiva, sacralizó el espacio público, trastocando el signo laico que se presupone propio de lo político.

\section{Hacia una antropología del acontecimiento}

En primer término, es importante señalar que a lo largo de mi trabajo de investigación, en el que me he esforzado por tratar de descifrar las claves y los 
distintos modos en que operan los acontecimientos disruptivos, ${ }^{1}$ es decir aquellos que irrumpen en la vida de las comunidades trastocando las rutinas, la dinámica y el sentido con el que la gente interpreta el mundo, he podido establecer una pequeña premisa: todo acontecimiento instaura sus propias reglas de lectura y configura su propio "espacio público", estableciendo normas, pautas, códigos y metáforas.

En todo acontecimiento irruptivo se entremezclan una racionalidad histórica (la articulación estructural de larga duración) y una racionalidad de la comunicación (los modos del decir, representar y metaforizar el acontecimiento). En otras palabras, en el acontecimiento se enfrentan dos fuerzas en tensión, de un lado el esfuerzo del colectivo implicado (un grupo reducido o la sociedad en su conjunto) por dotar al acontecimiento de inteligibilidad histórica, de ubicarlo en un marco explicativo de larga duración tratando de retener los elementos que configuran el núcleo de significación profunda; de otro lado, la lucha por la producción de visibilidad, las estrategias simbólicas que organicen el ritual, la protesta, lo que a su vez genera una disputa por la elaboración y apropiación del imaginario en torno al acontecimiento. No se trata de oponer como procesos antagónicos a la historia y a la comunicación, sino de ubicar la especificidad de sus procedimientos y sus lógicas y el papel que juegan en la configuración y modulación de una "política del recuerdo". Lo que quiero enfatizar es que toda política del recuerdo ${ }^{2}$ se ancla en la tensión constitutiva abierta por la historia y la comunicación.

\section{El acontecimiento}

En 1992, un miércoles de Pascua, en un denso barrio popular, ocho explosiones consecutivas que provenían del sistema de drenaje profundo al que penetraron grandes cantidades de gasolina, ocasionaron la destrucción total de más de ocho kilómetros de calles, casas y edificios. El saldo, según los contables del poder, fueron 210 muertos: vecinos de la zona, mujeres, niños, ancianos, hombres que encontraron la muerte de una manera por demás dramática, y más de 2.500 heridos graves, que aún hoy, a través de la asociación "Abril en Guadalajara", siguen en la lucha por una justicia que no llegó y mantienen viva la memoria del aconte-

1 REGUILLO, Rossana. La construcción simbólica de la ciudad. Sociedad, desastre, comunicación. Guadalajara: ITESO/Universidad Iberoamericana, 1995.

2 A la que entiendo como la articulación de voluntades históricas, intersubjetivas e intencionadas, que configuran saberes y emociones, construyen sentido y valor y que, especialmente, organizan un campo discursivo -en sentido amplio- para resignificar un acontecimiento, lo que a su vez engendra prácticas, abierto a la reinterpretación y por consiguiente contrario a toda significación total y clausurada. 
cimiento que marcó un punto de inflexión definitivo para la ciudad y que cada año, el 22 de abril, convoca a un cada vez menor número de "memoriosos".

Sin tradición de lucha política, sin cuadros propios que articularan la protesta, los "damnificados" apelaron inmediatamente a dos espacios de "contención" para gestionar su miedo, su sorpresa, su dolor, construir vínculos y expresar su interpretación del acontecimiento: la dinámica de la vida barrial y el espacio de la religiosidad. Frente a las estrategias del gobierno para aislar y controlar el movimiento de protesta que rápidamente convocó a numerosos ciudadanos y ciudadanas no implicados directamente. Los vecinos de Analco (el nombre de la zona), organizaron "la resistencia", el acopio, la ayuda mutua, el establecimiento de un pliego petitorio, a través de sus propios recursos, movilizando la red de relaciones vecinales; al mismo tiempo apelaron a los símbolos, a los espacios (iglesias de la zona) y a una comprensión religiosa del acontecimiento, en pugna con el discurso de la jerarquía católica, que los invitaba a la resignación.

Lo primero que llamó mi atención fue que el símbolo central que articula- ba el movimiento independiente de damnificados era una especie de santuario profano, en el que se recurría a la tradición de los exvotos o retablitos ${ }^{3}$ como modo de expresión política de la protesta: anónimos, rudimentarios, dolorosos, esos "mensajes" no nombraban a las víctimas por su nombre, se trataba de "mi familia", "mi esposa", "mis hijos", "mi madre", lo que indicaba para mí y ahora, al compararlo con el Altar de Cromañón, de lo que hablaré más adelante, que se trataba de una enunciación con un destinatario supraterrenal que no requería mayores datos, era una comunicación íntima entre doliente y su dios. En el "santuario", que lo mismo servía para decir misas, hacer acopio de ayudas materiales, elaborar el boletín informativo y campamento improvisado para los que, sin casa, se rehusaban a habitar en los albergues oficiales, abundaban crucifijos, imágenes de la virgen de Guadalupe, santos rescatados de los escombros. Por ello, no resulta sorprendente que cada una de las muchas manifestaciones públicas que siguieron al 22 de abril estuvieran siempre encabezadas por estos símbolos "que hablaban del dolor y la protesta", que conducían la acción performativa y organizaban, tal vez sin quererlo, los límites del movi-

3 Se trata de dibujos, estampas, relicarios que la gente coloca en los santuarios para pedir o agradecer la intermediación divina en un asunto terrenal. Para un estudio en profundidad de sus implicaciones véase DURAND, J. Milagros en la frontera. Retablos de migrantes mexicanos a Estados Unidos. México: CIESAS/El Colegio de San Luis, 2001. 
miento en tanto la matriz religiosa instaurada tempranamente, pese a su enorme efecto aglutinador inicial, produjo el umbral de los alcances políticos del movimiento de los damnificados y sus múltiples y numerosos aliados. Quiero decir, el lenguaje de "lo religioso" actuó como un marco-soporte limitado y estrecho para el decir y el hacer políticos en el espacio público.

A estos símbolos religiosos se fueron agregando otros, cuya clave de sentido está también vinculada a la cultura popular: la lucha libre que constituye ese paisaje de héroes enmascarados, vengadores populares de los desprotegidos, que confronta la ley y amenaza siempre con declarar una nueva ley, a la manera de Benjamin, ${ }^{4}$ que deriva en una gran fascinación.

Se sumaron también los artistas plásticos, que encabezaron una entusiasta toma del espacio público e inundaron plazas y calles con una obra ácida y crítica que no se había visto en la ciudad. Aparecieron también los símbolos nacionales, el himno, la bandera, la patria y la reinvención de la música como dispositivo vehiculizador de la protesta.

Pero, a la manera de los gitanos: la suerte estaba echada y lo que comandó el proceso performativo, es decir la "racionalidad comunicativa", fue "lo religioso", lo numinoso que pautó el campo de enunciación y dramatiza- ción de la protesta y que imprimió su gesto a "las políticas del recuerdo" que no lograron deshacerse de "la conmiseración cristiana" y del "deber católico frente al sufrimiento del otro". En aquellos meses de 1992, intensos, efervescentes, caóticos, productivos, era difícil calibrar que la racionalidad COmunicativa que comandaba las expresiones sociales frente al acontecimiento, imprimiría para siempre una huella, un sello de marca que al tiempo que activó un importante y nada desestimable movimiento social, operó también como su freno y contención.

Hasta aquí puedo decir que toda acción performativa está atada a la historia y a las historias locales, en ella brotan la memoria de luchas e interpretaciones pasadas, la cultura de fondo, lo permanente y residual, lo silenciado por la secularización modernizadora.

En el caso de Cromañón, la discoteca con aspiraciones interclasistas que se ubicaba en una de las esquinas del mismísimo, popular y comercial del barrio de "Once", se asemeja en muchos sentidos -guardando las proporciones en torno a las causas y los efectos- a la tragedia de Guadalajara. La suma de varios factores, corrupción política y falta de responsabilidad social, por sintetizar, aunados a la contingencia, derivaron en una tragedia urbana de proporciones mayúsculas. El grupo de rock "Callejeros" celebraba el último de una serie de

4 BENJAMIN, Walter. Para una crítica de la violencia. Buenos Aires: Leviatán, 1995. 
conciertos masivos de temporada; el lugar elegido fue la discoteca "República de Cromañón”. Con dos grupos teloneros que habían "calentado" el ambiente, sobrecupo en el lugar cerrado, a los pocos minutos de empezar la ronda de "Callejeros" saltaron las bengalas que incendiaron rápidamente los techos adornados con banderolas de poliuriteno; la tragedia se desató rápidamente, la combustión de estos materiales libera un gas llamado "ácido cianhídrico", que resulta letal de manera fulminante, ya que, según los expertos, bloquea todas las enzimas respiratorias de las células y evita que ingrese oxígeno al organismo. En mis propias consultas con expertos, este gas -aunado a las llamas del incendio-, provoca que la gente que lo inhala se "queme por dentro". La falta de cualquier normatividad en torno a la seguridad de un local de estas características, la gran cantidad de jóvenes que violentando los reglamentos habían sido admitidos en el interior del local, agudizaron el desastre, en tanto, se reportó que varias de las salidas de emergencia estaban bloqueadas o no servían. El resultado: alrededor de 150 muertos en el lugar, a los que se irían sumando varios más a lo largo de los días, en distintos hospitales.

En medio del caos, los medios televisivos y escritos llegaron rápidamente al lugar, algunos testigos del "campamento de Cromañón”, a quienes pude entrevistar, me decían que antes incluso que los servicios médicos y policíacos: prime time asegurado. El acon- tecimiento quedó bautizado como "masacre en Cromañón". El zoom in enfocó inmediatamente a los padres de los jóvenes muertos y los fijó en el lugar "de la víctima".

En un gesto probablemente espontáneo lo primero en arribar al lugar fue una corona de flores, a la que siguieron objetos religiosos, imágenes, banderas argentinas, zapatillas usadas y manchadas (no es claro si estas zapatillas que impresionan al "peregrino" provienen de los cuerpos rescatados o han sido llevadas por los deudos y amigos). La calle Bartolomé Mitre (al 3000, según la nomenclatura bonaerense), casi a la altura del cruce con la famosa avenida Rivadavia, quedó interrumpida y cerrada por el emergente altar-santuario-lugar de la protesta, que fue creciendo con el transcurso de los días. Las marchas de duelo y de protesta no se hicieron esperar y a través de la reconstrucción mediática del acontecimiento y de algunas entrevistas, el signo fundamental se organizó en torno al aislamiento de la causa "única": Omar Chabán, el empresario dueño del local de Cromañón, que ha sido elevado a "monstruo", en lo que Barone, en el diario La Nación (3 de julio del 2005), denomina "gigantografía desaforada".

Pero más allá de la descripción de un suceso fatídico, otra vez, lo fundamental para esta discusión se centra en los lenguajes-soportes que vehiculizaron el sentido del acontecimiento. De manera parecida a las explosiones de Guadalajara, en torno a Cromañón, no 
tardaron en aparecer el "gauchito Gil" 5 y la "Virgen de Luján" (patrona indiscutible de la Argentina); pero de manera mucho más ambigua el santuario se cargó de imágenes complejas, profanas, "atrapadores de sueños", zapatillas, rosarios, budas y mensajes poéticos. Y de manera diferente al caso "Guadalajara", en el altar de Cromañón aparecieron fotografías de las víctimas y una obsesiva apelación al nombre propio.

Si como planteé anteriormente, todo acontecimiento y su efecto performativo hunde sus raíces en las historias locales, no es entonces extraño que en el caso testigo argentino se recurriera a la memoria del duelo y a las estrategias performativas de la protesta por las víctimas y desparecidos de la dictadura: el nombre propio, la fotografía, la ubicación concreta de cada uno de los afectados. Pero, al visitar el santuario de Mitre, ${ }^{6}$ se constata que lo que se impone no es "la estética" del memorial de la lucha por los desaparecidos y la justicia como verdad, sino el signo de lo religioso y de la fatalidad; el nombre mismo del campamento que mantienen algunos padres y jóvenes en el lugar es revelador: "Ángeles de Cromañón”. En una hipótesis interpretativa podría decirse que se trata de dos lenguajes que no empatan y que los símbolos "seculares" y políticos quedan como sobrepuestos o siguen otra sintaxis y estructura, como si se tratara de dos discursos contrapuestos que provinieran de enunciatarios distintos.

Pese a las estrategias diferenciales de producción de visibilidad, en lo que toca a la racionalidad comunicativa, ambos acontecimientos quedan, al final, atrapados en el lenguaje de lo numinoso, de la justicia vengadora, sus protagonistas devienen "dolientes", o en la terminología de Goffman, "comunidad de sufrientes", lo que diluye la identidad ciudadana del colectivo. Si como apunta Kaufman a propósito del acontecimiento Cromañón, al referirse a lo que constituyó el "único discurso público sobre el desastre”, que “... [lamentablemente] se seleccionó a aquellos que estuvieran animados en sus intervenciones por el dolor más desgarrador, por el llanto incontenible en muchos casos, y en otros por una ira vindicatoria puesta en palabra y en actos"

5 El gauchito Gil (Antonio Mamerto Gil Núñez) es un personaje de la devoción popular argentina, que se origina en las luchas entre liberales y autonomistas por allá por 1847. Con resistencias para incorporarse a las filas de los liberales, el "gauchito" se refugió en los montes, donde creció su leyenda como bandolero "bueno" (que a la manera de Robin Hood, robaba a los ricos para darle a los pobres). Ajusticiado por el cuchillo de un sargento a las órdenes del coronel Salazar, "el Gauchito" vaticinó la desventura del sargento por derramar sangre inocente, profecía que se cumplió. Ahí se origina su culto y devoción.

6 Hice dos levantamientos etnográficos y fotográficos en momentos distintos, en junio y en octubre del 2005. Además, tuve la suerte de conocer el trabajo fotográfico que sobre el "Altar" levantó la antropóloga Luzmila Catela da Silva. 
(Página/12, 30 de junio del 2005), podría aventurarse que hay una solución de continuidad, una colaboración entre el discurso de los grandes medios y las culturas populares, que convierte, como diría Anderson, "la contingencia en significado y el azar en destino". 7

La significación cultural dominante de estas catástrofes urbanas revela una matriz profunda, una concepción religiosa del mundo, lo que a su vez potencia la lógica de la fatalidad y la emergencia del lugar de la víctima. El acontecimiento es así un potente revelador de la cultura profunda que los afectados "ponen a funcionar" frente a la desestructuración del tejido material y simbólico de su entorno inmediato, pero que encuentra en la sociedad un soporte-complicidad en unas sociedades, la mexicana y contra todo estereotipo también la argentina, donde, en palabras del antropólogo Pablo Seman:

... la experiencia popular es cosmológica (...) y supone que lo sagrado es un nivel más de la realidad. La experiencia cosmológica de los sectores populares no ha perdido esas referencias que, en todo caso, fueron roídas por algunos de los avances de la modernidad y, sobre todo, obliteradas por el obstáculo epistemológico que representa el modernocentrismo. ${ }^{8}$
No resulta misterioso que acontecimientos irruptivos que sacuden los cimientos profundos en los que se asienta una sociedad, aun siendo propios de la sociedad del riesgo, conecten el sensorium con esas referencias "roídas, obliteradas" pero vigentes y actuales, y que sean ellas quienes comanden el proceso de una racionalidad comunicativa que en su esfuerzo por acceder a la palabra y al acto recurre a los saberes de fondo.

Si el análisis aquí propuesto se sostiene, no son pocas las preguntas que surgen. De cara a unas políticas del recuerdo, cómo pensar el acontecimiento irruptivo más allá de sus implicaciones inmediatas y su rango de acción en un espacio-colectivo restringido; cómo pensar el dolor de las víctimas sin violentar sus propios procesos, atrayendo el acontecimiento hacia una esfera pública que logre trascender la interpretación "numinosa" y hacer de él un espacio para la reflexividad. Cómo dar paso a unas "políticas del recuerdo" que, articulando antagonismos, históricamente situadas e intersubjetivamente compartidas, configuren un campo discursivo que reactive la dimensión política del acontecimiento emblemático, en la tensa contradicción entre la significación clausurada y la interpretación abierta.

7 ANDERSON, Benedict. Comunidades imaginadas. Reflexiones sobre el origen y la difusión del nacionalismo. México: Fondo de Cultura Económica, 1993, p. 29.

8 SEMAN, Pablo. "¿Por qué no?: El matrimonio entre espiritualidad y confort. Del mundo evangélico a los bestsellers". Desacatos 18. Revista de Antropología Social. (Mercado y Religión Contemporánea). México: CIESAS, mayo-agosto del 2005, p. 84. 


\section{Ciudad interrumpida... performatividad y disputas por la memoria}

Qué significa la irrupción de un acontecimiento en la vida de una ciudad, cómo pensar la catástrofe urbana como lenguaje que obtura la idea e imagen de la continuidad, cómo imaginar la ciudad a partir de las múltiples, complejas y sucesivas emergencias, que más allá de testimoniar la fragilidad de un orden presupuesto, señalan la precariedad de un pacto social elaborado sobre la idea de continuidad y estabilidad. Contra el sentido común, la ciudad es cualquier cosa menos seguridad, es, pese a los esfuerzos planificadores, el lugar del accidente y de lo ambiguo.

Guadalajara señaló las terribles consecuencias de la corrupción política y económica; Cromañón marcó la irresponsabilidad (corrupta) sobre los riesgos urbanos. Ambos sucesos instauran grandes cicatrices en el tejido urbano, re-escriben la geografía simbólica de la ciudad y abren un calendario cíclico, "una fecha" cuyo sentido es la de certificar un "antes" y un "después" en la ciudad.

En la potencia articuladora y eventualmente transformadora del ritual performativo, clave hoy en una sociedad que no puede prescindir del lenguaje inter-medial del símbolo hecho acción, se opera una llamada a una emocionalidad que resulta "indecible" desde el lenguaje oficioso de la política. Esa es su potencia, su especificidad, hablar en el registro de lo no enunciable más que por el performance, que rompe las costuras, los límites, los bordes del texto "serio" de la política. Pero ello no significa que la expresión performativa constituya un lenguaje residual o una gramática "por defecto".

Quizás lo más relevante en la relación entre acontecimiento, lugar y performatividad radica en que el lenguaje estético-simbólico de esta última opera un puente entre el tiempo extraordinario de la protesta y el tiempo ordinario de la vida cotidiana, entre lo estructural y lo coyuntural, que al retornar al centro del espacio público, abre las condiciones para la emergencia de unas políticas del recuerdo, abiertas a la reinterpretación política y cultural y a la re-actualización semiótica. Dos lenguajes y dos lógicas que pueden, no obstante, encontrar solución de continuidad en la producción de lenguajes simbólicos que sin anular las diferencias de ambos tiempos y ambas territorialidades logren mostrar la imbricación profunda entre lo privado y lo público. En tal sentido, las marcas de una religiosidad popular (híbrida, desjerarquizada, ambigua), que orientaron y codificaron la racionalidad comunicativa dominante de los dos casos testigos aquí reflexionados, pese a la energía producida... facilitan su apropiación por parte tanto de los flujos mediáticos como del poder, no al desdramatizar el acontecimiento sino al clausurar su signo y su interpretación, 
generando un campo discursivo en que solo es posible retener la tragedia y la victimización. Pienso que de maneras diferenciales, ambos acontecimientos aportaron los símbolos "fáciles" que impiden salir del campo discursivo de la revancha vengadora, lo que impide hacer de las políticas del recuerdo un espacio-dispositivo para la transformación de la estructura.

Al pensar en Cromañón acuden las imágenes de los cientos de zapatillas sin cuerpos que las anden, al pensar en Analco, vienen las imágenes de santos destrozados sin paredes que las sostengan. La acción performativa enderezada por los afectados y sus aliados en extenso, no logró la expansión del signo político y terminó por convertir "los movimientos sociales de protesta" en rehenes de su propia fotografía.

\section{La víctima y sus reversos}

Con Nelly Richard, ${ }^{9}$ intento interrogarme si hay una "sobreactuación del recuerdo", una retórica de la elocuencia que en su expresión designe otro límite que no sea el de la incomunicabilidad, el de la clausura definitiva de toda posibilidad re-interpretativa del pasado.

Retorno al epígrafe de este ensayo: "Edmundo Dantés no ha perdonado", creo que Augé desenfoca el ángulo clave de su crítica. No es la ausencia de perdón, ni siquiera la obsesión por el pasado, lo que condena a Dantés, a una "doble desgracia", es su imposibilidad de salir del lugar de la víctima, condenado por su propia biografía y su subjetividad a encarnar, en un después, el papel del verdugo, Dantés no logra abandonar "la clave piadosa" en su propia explicación sobre su condición de víctima; solo hay lugar, entonces, para la venganza en una eterna exclusión del futuro, en una "política del recuerdo" que no logra solución de continuidad entre lo que Richard llamaría "memoria-objeto, memoria-sujeto” (p. 126). Así las víctimas de Analco y las víctimas de Cromañón quedan atadas a "los prestigios" que al tiempo que los constituyen en sujetos de un proceso, los condenan al lugar de la biografía personal, descontextualizada de los marcos estructurales que forzosamente explican su existencia.

Si en la disputa por las geografías de la ciudad, por el memorial que debe operar todo proceso de continuidad entre el pasado y el futuro no hay sujetos sociales, históricamente situados, solo víctimas y santuarios, resulta difícil imaginar estrategias que devengan unas políticas del recuerdo capaces de restituir el lugar del ciudadano y del proyecto colectivo.

9 RICHARD, Nelly. "Con del 11 de septiembre. Notas sobre La memoria obstinada (1996) de Patricio Guzmán”, en JELIN, Elizabeth y Ana LONGONI (comps.). Escrituras, imágenes y escenarios ante la represión. Madrid: Siglo XXI Editores, 2005, p. 127. 
Los reversos de la víctima están en el espacio de inscripción del sujeto histórico y social; por ello, para terminar, quisiera apelar a un pequeño relato etnográfico que problematiza no solo lo aquí dicho, sino mi mirada sobre esa enunciación, el papel del testigo sin el cual ninguna performance alcanza su sentido:

Isabel tenía una mirada envejecida en un cuerpo de niña; tenía por aquel entonces apenas once años y, aún hoy, casi quince años después, no puedo dejar de pensar en ella como el epicentro del acontecimiento que le cambió el rostro a la ciudad en la que vivo. Isabel es para mí el nombre de una enorme tragedia y es al mismo tiempo la memoria viva de la voluntad y la fuerza; por supuesto, de la vida. Tres imágenes en el recuerdo se instalan como cicatrices vivas en mi memoria: la veo de la mano del luchador social de "lucha libre", el "Ecologista Universal Uno", al frente de una gigantesca marcha que reclamaba al gobierno mexicano su incapacidad, corrupción, debilidad frente a las consecuencias de una serie de explosiones en la ciudad de Guadalajara que se llevaron a más de doscientas personas y sumieron a una zona densamente poblada en una pesadilla de dolor e injusticias; de manera extraña no puedo verla sino a través de la lente de mi cámara de video, que registra, obsesivamente, todos los movimientos de los damnificados por las explosiones de gasolina en abril de 1992, en la ciudad. Si en la memoria del presente aparto la vista de la cámara, solo accedo a un gran vacío: no están ni Isabel, ni el "Ecologista", ni Nachito, ni los demás niños que encabezaron esa dramática marcha por la justicia y dieron una lección a esta ciudad tan apegada a la tranquilidad y al "aquí no pasa nada”. ¿Es Isabel un cuadro de video?, ¿es ella (y los demás) una figura accesoria o residual de los afanes de una investigadora?, ¿un lugar anónimo en la estructura? No, recupero a Isabel y a los demás niños, jóvenes, señoras, días después: en retrospectiva. Hoy, logro levantar los ojos de la cámara y me enfrento a una Isabel angustiada pero sonriente: estamos en un juzgado penal. Los policías que días atrás han golpeado y amenazado a los damnificados en el campamento que han levantado en el centro de la ciudad, han sido localizados y detenidos, confrontados con las mujeres, los niños y los hombres que han sido -otra vez- golpeados, amenazados, sometidos. Ella declara ante un agente del Ministerio Público, temerosa pero eficiente, abierta, sincera, transparente; no puedo sino "acompañarla" con mi propia cámara: certifico sus palabras, la acompaño con imágenes para testimoniar que "su memoria" no miente (que yo, otros, estuvimos ahí), corroboro, mientras un sabor salado se me instala en la garganta, allá en aquel juzgado, y hoy, cuando esto escribo, la veo levantarse (orientada, claro, por los asesores populares que saben de estas cosas) para entregarle una rosa al policía que la 
madrugada atrás pasó por encima de su cuerpo sin escrúpulos ni remordimientos, sabiéndose a salvo porque a esas horas de la madrugada, en un campamento de "residuales", no hay testigos, ni cámaras, ni periodistas, apenas unos pocos y poco creíbles defensores de derechos humanos, cuya memoria es siempre tan fácil de anular. Pero Isabel no se arredra, su cuerpo de once años narra para todos y la mujer que escribe en una anacrónica máquina de escribir -que retorna a preguntar y a preguntar-, de manera obsesiva los minutos de ese día en que la vida le cambiaría para siempre: dice otras cosas, pero su voz de niña afirma "no hicimos nada para merecer esto, no gritamos, no golpeamos a nadie, no rompimos cercas ni alambrados, ni siquiera gritamos nada que no fuera pedir justicia. Isabel sabe lo que recuerda y se convierte en la memoria viviente donde "nacional, lo familiar, lo heroico, lo privado, lo público, lo amoroso, lo cotidiano" (ibídem), quedan lamentablemente disociados de la interpretación clausurada del acontecimiento. Pese a sus intentos por restituir complejidad política, Isabel queda fija en el lugar de la víctima.

\section{Bibliografía}

ANDERSON, Benedict. Comunidades imaginadas. Reflexiones sobre el origen y la difusión del nacionalismo. México: Fondo de Cultura Económica, 1993.
AUGÉ, Marc. Las formas del olvido. Barcelona: Gedisa, 1998.

BARONE, Orlando. "El rating del santuario perpetuo". La Nación. Buenos Aires, 3 de julio del 2005.

BENJAMIN, Walter. Para una crítica de la violencia. Buenos Aires: Leviatán, 1995.

DURAND, Jorge. Milagros en la frontera. Retablos de migrantes mexicanos a Estados Unidos. México: CIESAS/El Colegio de San Luis, 2001.

KAUFMAN, Alejandro. "Lógicas de linchamiento". Página/12. Buenos Aires, 30 de junio del 2005.

REGUILLO, Rossana. La construcción simbólica de la ciudad. Sociedad, desastre, comunicación. Guadalajara: ITESO/Universidad Iberoamericana, 1995.

RICHARD, Nelly. "Con del 11 de septiembre. Notas sobre La memoria obstinada (1996) de Patricio Guzmán”, en JELIN, Elizabeth y Ana LONGONI (comps.). Escrituras, imágenes $y$ escenarios ante la represión. Madrid: Siglo XXI Editores, 2005.

SEMAN, Pablo. "¿Por qué no?: El matrimonio entre espiritualidad y confort. Del mundo evangélico a los bestsellers". Desacatos 18. Revista de Antropología Social. (Mercado y Religión Contemporánea). México: CIESAS, mayo-agosto del 2005. 